\title{
Efficient Clearance of Non-transferrin-bound Iron by Rat Liver Implications for Hepatic Iron Loading in Iron Overload States
}

\author{
Pierre Brissot, Teresa L. Wright, Wei-Lan Ma, and Richard A. Weisiger \\ Department of Medicine and Liver Center, University of California, San Francisco, California 94143
}

\begin{abstract}
In hemochromatosis and other disorders associated with iron overload, a significant fraction of the total iron in plasma circulates in the form of low molecular weight complexes not bound to transferrin. Efficient and unregulated clearance of this form of iron by the liver may account for the hepatic iron loading and toxicity that characterize these diseases. We tested this possibility by examining the hepatic removal process for representative iron complexes in the single-pass perfused rat liver. Hepatic uptake of both ferrous and ferric ${ }^{55}$ Fe from ultrafiltered human serum was found to be highly efficient and effectively irreversible (single-pass extraction of $1 \mu \mathrm{M}$ iron, 58-75\%). Similar high efficiencies were seen for iron complexed to specific physiologic and nonphysiologic coordinators, including histidine, citrate, fructose, oxalate and glutamate, and tricine. Because of lower plasma flow rates, single-pass extraction of these iron complexes in vivo should be even greater. Autoradiography confirmed that most iron had been removed by parenchymal cells. Hepatic removal from Krebs-tricine buffer was saturable with similar kinetic parameters for ferrous and ferric iron (apparent $\boldsymbol{K}_{\mathrm{m}}$, 14-22 $\mu \mathrm{M} ; V_{\max }, 24-38 \mathrm{nmol} \mathrm{min}^{-1} \mathrm{~g}$ liver $^{-1}$ ). These findings suggest that high levels of non-transferrin-bound iron in plasma may be an important cause of hepatic iron loading in iron overload states.
\end{abstract}

\section{Introduction}

Despite its potential for toxicity, iron is an essential cofactor in the metabolism of all mammalian cells. As a result, regulatory mechanisms have evolved that closely control the absorption and distribution of iron within the body. Most iron circulates tightly bound to transferrin, a plasma glycoprotein. Tissue uptake of this form of iron has been well-characterized, and seems to be regulated by the number of receptors for transferrin expressed on the cell surface (1-4). The uptake process mediated by these receptors typically removes $<1 \%$ of the iron from plasma as it passes through the liver (5).

In contrast, the uptake of non-transferrin-bound (NTB) ${ }^{1}$ iron

This work was presented at the Plenary Session of the American Association for the Study of Liver Diseases, New Orleans, LA, May 1984.

Dr. Brissot's current address is Liver Research Unit, Inserm Unit 49, Pontchaillou Hospital, Rennes, France. Address correspondence to Dr. Weisiger, Department of Medicine, $1120 \mathrm{HSW}$, University of California, San Francisco, CA 94143.

Received for publication 17 December 1984 and in revised form 23 April 1985.

1. Abbreviations used in this paper: NTB, non-transferrin bound.

J. Clin. Invest.

(c) The American Society for Clinical Investigation, Inc.

0021-9738/85/10/1463/08 $\$ 1.00$

Volume 76, October 1985, 1463-1470 has received much less attention. NTB iron is defined as that iron in plasma that is not complexed by transferrin, and is thought to consist of a mixture of iron complexes with ascorbate, carbonate, certain amino acids, carbohydrates, hydroxide, certain organic acids, and, to a lesser degree, plasma proteins such as albumin $(6,7)$. In normal individuals, the plasma concentration of NTB iron is extremely small (7-9). However, much higher concentrations have been reported in hemochromatosis (9) and transfusional iron overload (8), possibly reflecting saturation of the binding capacity of transferrin. If the hepatic uptake process for this form of iron is both efficient and unregulated, high plasma levels of NTB iron could be the proximate cause of hepatic iron loading and toxicity in hemochromatosis and other iron overload states. To test this hypothesis, we studied the uptake of representative NTB iron complexes in the perfused rat liver.

\section{Methods}

Sources of chemicals. Ferrous sulfate and citric acid were obtained from Mallinckrodt Inc. (Paris, KY); bovine serum albumin (fraction V, essentially fatty acid-free), human albumin (crystallized and lyophilized, essentially globulin-free), L-histidine hydrochloride, L-glutamic acid, Dfructose, L-ascorbic acid, tricine ( $N$-tris[hydroxymethyl]methylglycine), and bathophenanthroline were obtained from Sigma Chemical Co. (St. Louis, MO); oxalic acid was obtained from Eastman Kodak (Rochester, NY); dimilume 30 scintillant from Packard Instruments, Inc. (Downers Grove, IL); and the fluorocarbon emulsion (Oxypherol FC-43) from Alpha Therapeutics (Los Angeles, CA). ${ }^{55} \mathrm{Fe}\left(5.84 \mathrm{mCi} \mathrm{mg}^{-1}\right)$ was obtained as the citrate from New England Nuclear (Boston, MA).

Solution preparation and validation. The normal perfusion solution was a modified Krebs-Henseleit buffer containing $128 \mathrm{mM} \mathrm{Na}^{+}, 145$ $\mathrm{mM} \mathrm{Cl}^{-}, 5.9 \mathrm{mM} \mathrm{K}^{+}, 1.2 \mathrm{mM} \mathrm{Mg}^{++}, 2.5 \mathrm{mM} \mathrm{Ca}^{++}, 1.2 \mathrm{mM}$ phosphate, $1.2 \mathrm{mM} \mathrm{SO}_{4}^{--}, 11.5 \mathrm{mM}$ glucose, and $10 \mathrm{mM}$ tricine base in deionized water, and was prepared daily from concentrated stocks. Solution $\mathrm{pH}$ was adjusted to 7.4 at $24^{\circ} \mathrm{C}$ with $0.1 \mathrm{~N} \mathrm{HCl}$, resulting in a pH of 7.31 at $37^{\circ} \mathrm{C}$. All solutions, except those containing ferrous iron, were equilibrated with $100 \% \mathrm{O}_{2}$ at $37^{\circ} \mathrm{C}$ before use. Ferrous iron solutions were prepared using buffer that had been rendered anaerobic by vigorous bubbling with $100 \% \mathrm{~N}_{2}$ for at least 30 min and were kept under $\mathrm{N}_{2}$ during use. Ferric iron solutions were prepared by autooxidation of the corresponding ferrous solution under $100 \% \mathrm{O}_{2}$. Assay of these solutions by the method of Bothwell et al. (10) confirmed that oxidation to ferric iron was virtually complete within $1 \mathrm{~min}$ after addition of oxygen, while ferrous iron solutions with and without ascorbate remained stable for at least $4 \mathrm{~h}$. To assess the degree of aggregation of the iron in the perfusate solutions, we measured the initial rate of diffusion of ferrous and ferric iron across a cellulose membrane $(2.5-\mathrm{cm}$ diam, molecular weight cut off, 2,000 [Spectrum Medical Industries, Inc, Los Angeles, CA]) at $37^{\circ} \mathrm{C}$. In these studies, $4 \mathrm{ml}$ of tricine buffer was dialyzed against $160 \mathrm{ml}$ of perfusate for $60 \mathrm{~min}$ and the ratio $(R)$ of radioactivity inside the bag to that in the perfusate was determined for each concentration used in the perfusion experiments $(1-60 \mu \mathrm{M})$. The half-life for equilibration was determined from the expression, $\mathrm{t}_{1 / 2}=60 \mathrm{~min} \times \log (0.5) / \log (1-R)$. In a limited number of perfusions designed to assess the effect of physiologic iron coordinators on uptake, bicarbonate $(5.9 \mathrm{mM})$ was used in place of tricine and $5 \% \mathrm{CO}_{2}$ was added to the equilibrating gas. Deproteinized 
human serum was prepared by ultrafiltration of fresh serum through a PM 30 membrane (Amicon Corp., Danvers, MA). To minimize iron binding, we acid-washed all glass containers (including test tubes), dried them thoroughly, and siliconized them by immersion in a solution of $5 \%$ dimethyldichlorosilane in toluene for $1 \mathrm{~h}$. Glassware was rinsed in distilled water and dried before use.

Perfusion apparatus. Livers were perfused in a modified lucite cabinet (Air Control 0432112; Huntingdon Valley, PA) with humidified and independently thermoregulated upper and lower chambers. In this system (Fig. 1), the isolated liver, perfusion pump (Multiperpex 2115, [LKB Instruments, Inc., Pleasant Hill, CA]), tubing lung (11), valves for selection of perfusate solutions, and all single-pass perfusate flasks were in a sealed upper chamber, while a $50-\mathrm{ml}$ reservoir for the recirculating perfusate was in the lower chamber. During recirculating perfusion, the effluent stream was captured by this reservoir and recycled in sequence through the pump, tubing lung, in-line filter (XX3002510 [Millipore Corp., Bedford, MA]), pH probe (PHM84 [Radiometer, Copenhagen, Denmark]), and an inverted " $Y$ " tube manometer, which also served as a bubble trap. To convert to single-pass perfusion, we moved the reservoir from beneath the liver to allow collection of samples from the effluent stream and also moved a rotary valve (Rheodyne 5012) used to select the pump input from one of up to six solutions pre-equilibrated with the specified gas mixture. To minimize deadspace, we used a separate vale (Rheodyne 5012) to bypass the lung, filter, $\mathrm{pH}$ probe, and manometer while in the single-pass mode. By use of minimal lengths of small-bore polyethylene tubing (PE 205 [Clay Adams, Parsippany, NJ]), the time required for a new solution to reach the liver was reduced to $\sim 6 \mathrm{~s}$ at typical flow rates. Before initial use, latex tubing was rinsed with acetone overnight. Liver temperature was monitored during perfusion with a thermister probe (Yellow Springs 427) positioned between the lobes of the liver and regulated to $37 \pm 0.5^{\circ} \mathrm{C}$ by thermostatic control of the air temperature in the upper chamber. Humidity was maintained near $100 \%$.

Surgical procedure. Livers from 55-65-d-old fed male Sprague Dawley rats were surgically removed by a modification of the procedure of Hems et al. (12). The peritoneal cavity was opened under light ether anaesthesia and a $15-\mathrm{cm}$ PE-10 polyethylene catheter secured in the common bile duct. After partial mobilization of the liver from adjacent tissues, a 16gauge teflon intravenous catheter (Angiocath 2814; The Deseret Co., Sandy, UT) was introduced into the portal vein and $2.5 \mathrm{ml}$ of perfusion buffer, containing $1,000 \mathrm{U}$ of heparin injected over several seconds using a 3-ml syringe. The catheter was tied in place and the liver perfused at a rate of $\sim 5 \mathrm{ml} \cdot \mathrm{min}^{-1}$ with buffer from a temporary perfusate reservoir
(Krebs bicarbonate buffer maintained at $37^{\circ} \mathrm{C}$ and bubbled with $95 \%$ $\mathrm{O}_{2}, 5 \% \mathrm{CO}_{2}$ ) using gravity flow. The inferior vena cava was ligated above the renal veins and transected distally. The thorax was opened and a PE-205 polyethylene catheter secured in the superior vena cava through an incision in the right atrium. The liver was then carefully removed, placed on a nylon mesh to facilitate handling $(80-\mathrm{mm}$ diam with a central 10-mm hole and radial slit), and rinsed with warm saline. After temporary obstruction of the outflow catheter, the portal vein catheter was reconnected to the perfusion system containing $50 \mathrm{ml}$ of $20 \%$ fluorocarbon emulsion pre-equilibrated with $95 \% \mathrm{O}_{2}, 5 \% \mathrm{CO}_{2}$ in the recirculating mode $\left(5 \mathrm{ml} \cdot \mathrm{min}^{-1}\right)$. The liver was lowered onto the perfusion platform (a 10-cm petri dish with a central opening) and the position of the inflow and out-flow catheters was carefully adjusted. The flow rate was then gradually advanced to $20-25 \mathrm{ml} \cdot \mathrm{min}^{-1}$ while monitoring the pressure for evidence of obstruction.

Perfusion protocol. After a 30-min stabilization period during which the lung was gassed with pure $\mathrm{O}_{2}$ plus sufficient $\mathrm{CO}_{2}$ to maintain the perfusate $\mathrm{pH}$ at 7.4, the apparatus was switched to the single-pass mode and the bypass valve was set for direct flow of the perfusate from the pump to the liver. The liver was then perfused with oxygenated buffer for $4 \mathrm{~min}$ to wash out the fluorocarbon emulsion. During this period, the flow rate was advanced to $\sim 2.6 \mathrm{ml} \cdot \mathrm{min}^{-1} \cdot \mathrm{g}^{-1}$ liver and carefully measured by timed collection.

In most experiments, the liver was then perfused with a sequence of test solutions containing graded concentrations of ferrous or ferric iron (30 s each). Each test solution was followed with a 60-90-s wash with oxygenated perfusion buffer. The effluent stream was sampled after steady-state had been achieved (typically $<25 \mathrm{~s}$ ) and at intervals during the washout phase, using siliconized glass tubes $(10 \times 75 \mathrm{~mm})$, each of which contained $25 \mu \mathrm{l}$ of $10 \%$ bovine albumin to further minimize binding of iron to the glass. Control experiments indicated that samples were stable for at least $3 \mathrm{~h}$ under these conditions. ${ }^{55} \mathrm{Fe}$ was quantitated in triplicate by scintillation counting in Dimilume (Packard Instruments, Inc.).

Data analysis. The rate of iron removal by the liver at steady-state $(V)$ was calculated according to $\mathrm{Eq} .1$ below, where $C$ is the concentration of iron in the entering perfusate, $F$ is the flow rate (liters $\left.\cdot \min ^{-1}\right), E$ is the fraction of the iron extracted by the liver in a single pass, and $W$ is the wet weight of the liver (g).

$$
V=\frac{C \times F \times E}{W} \text {. }
$$

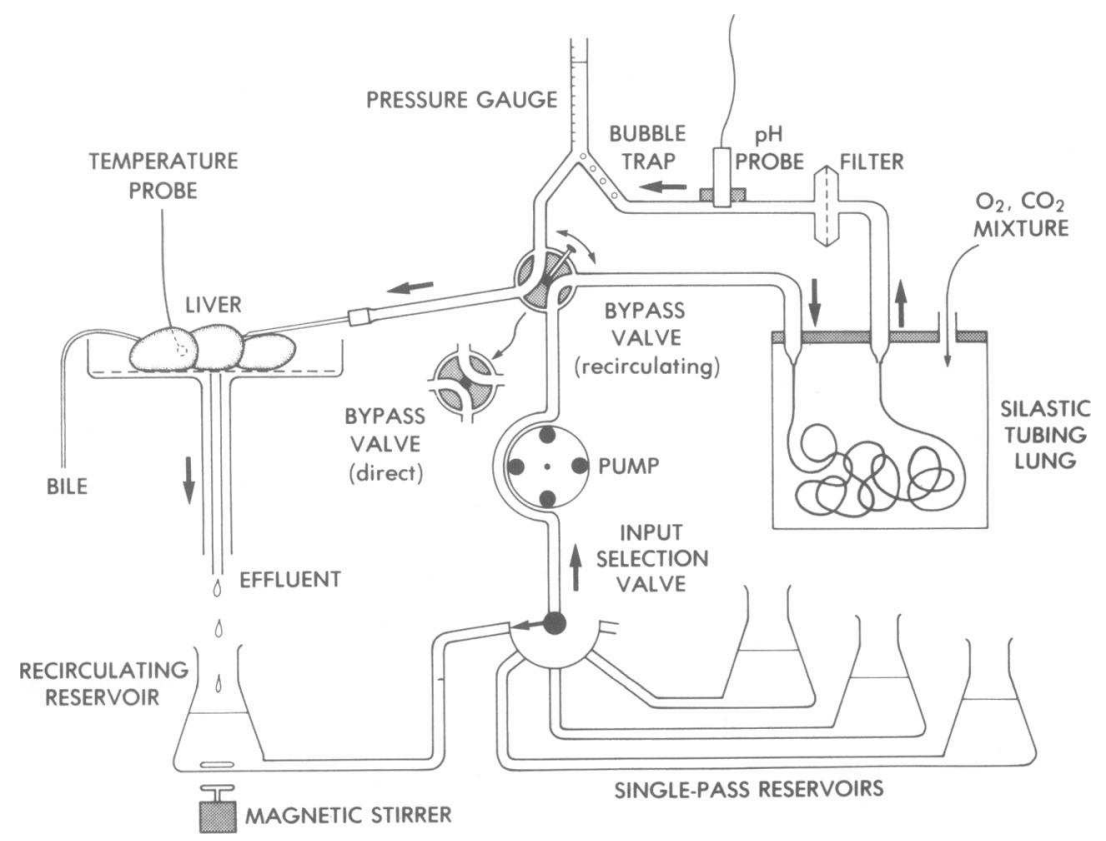

Figure 1. Liver perfusion system. In the recirculating mode, the perfusate flowing from the liver is recirculated through the pump, membrane lung, filter, $\mathrm{pH}$ probe, and bubble trap. After a 30-min stabilization period, the apparatus is converted to single-pass mode and the steady-state fractional extraction of iron measured for a series of solutions selected using the input valve. Validation requires that the extraction measured for the initial solution be reproduced at the end of the experiment. The bypass valve is used to exclude system components that are not needed for single-pass perfusion. 
Data for individual experiments were analyzed by nonlinear leastsquares curve fitting in which the uncertainty of each data point was assumed to be proportional to its magnitude (weighting power $=2$ ). Models with up to two saturable uptake components with and without a nonsaturable uptake component were considered for representing the data. A single saturable uptake component was found to adequately account for the data. More complicated models did not result in a significant improvement in the fit and had large uncertainties in the derived parameters. Results for replicate studies were averaged. Statistical significance was assessed by use of the Student's $t$ test.

This method of analysis assumes that each hepatocyte has a similar uptake capacity and is exposed to the same concentration of iron. However, since the hepatocytes are actually exposed to concentrations of iron ranging from that entering the liver to that in the effluent stream, this is an oversimplification. Recalculation based on the effluent rather than the entering iron concentrations resulted in relatively small changes in the kinetic constants (apparent $K_{\mathrm{m}}$ reduced $\sim 35 \%$ with no effect on the apparent $V_{\max }$ ). In this study, the uptake rate is related to the entering iron concentration, since this value is most often clinically available.

Microscopic studies. After selected experiments, livers were postperfused with iced $2.7 \%$ glutaraldehyde plus $0.8 \%$ paraformaldehyde and prepared for light and electron microscopy using standard methods. Loss of radioactivity during processing of the tissue was $<5 \%$. Thin sections $(0.2 \mu \mathrm{m})$ were coated with Kodak nuclear track emulsion NTB2, and developed in Kodak D-19 developer after a 4-8-week exposure period.

\section{Results}

Microscopy. Electron microscopy showed excellent preservation of detail with no evidence of toxicity, even after $30 \mathrm{~min}$ of perfusion with $1 \mu \mathrm{M}$ ferrous iron (Fig. 2). Ultrastructural features appeared completely normal. Light microscopy was normal, except for a slight widening of the sinusoidal spaces (Fig. 3). This change appeared to result from replacement of bicarbonate with tricine, since it was not seen in livers perfused with bicarbonate buffers alone.

Solution validation. Ferric iron was freely and equally diffusible at all concentrations used in these studies (Fig. 4), which indicates that it exists in a low molecular weight form in Krebstricine buffer. Identical results were found for ferrous iron (data not shown). Mean half-times for equilibration across the dialysis membrane were $101 \pm 9$ and $96 \pm 5 \mathrm{~min}$, respectively $(P>0.5)$,

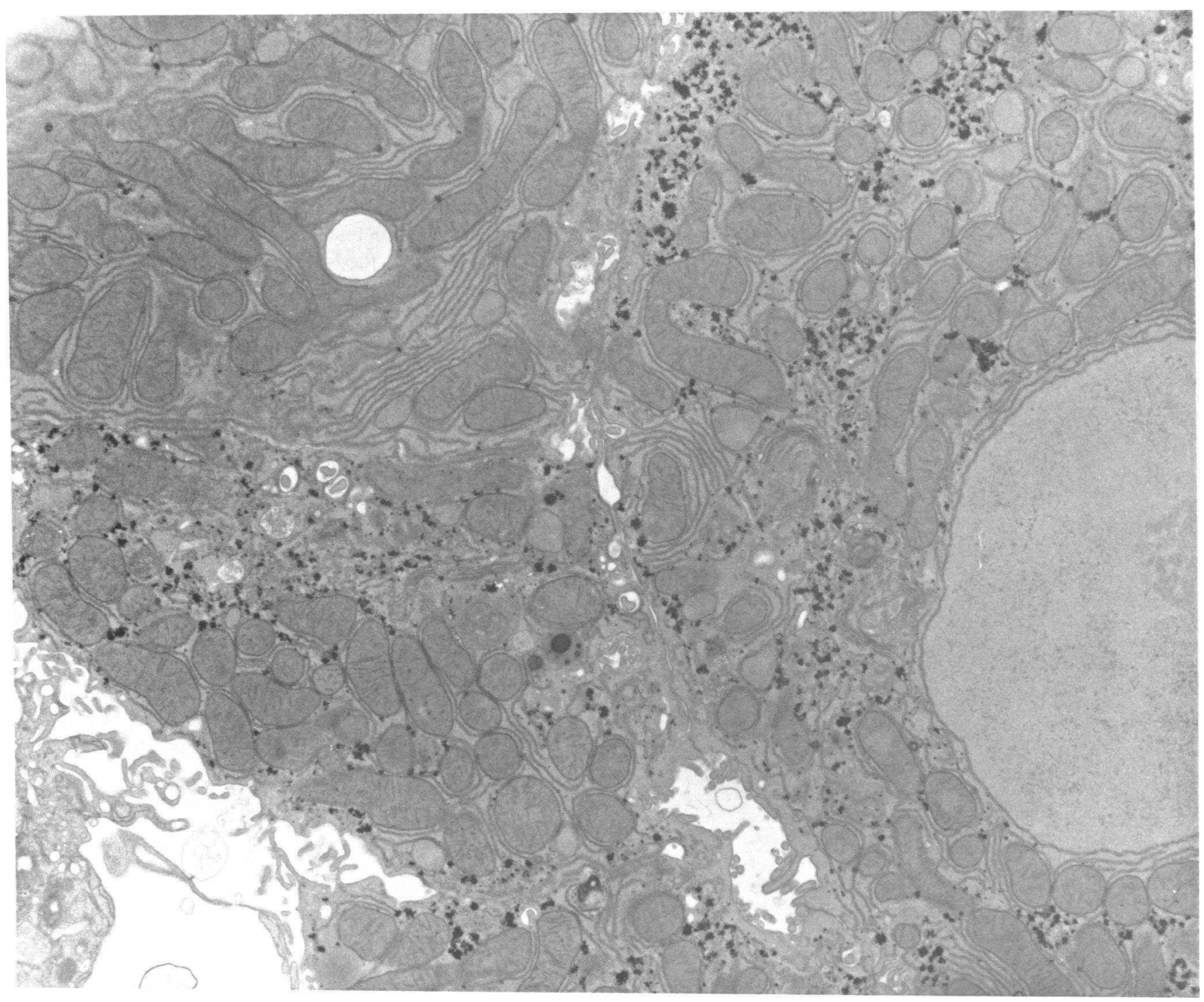

Figure 2. Electron micrograph of liver following perfusion. The liver has been perfused single-pass with $1 \mu \mathrm{M}$ ferrous ascorbate in tricine buffer for $30 \mathrm{~min}$. Normal ultrastructure is seen. 


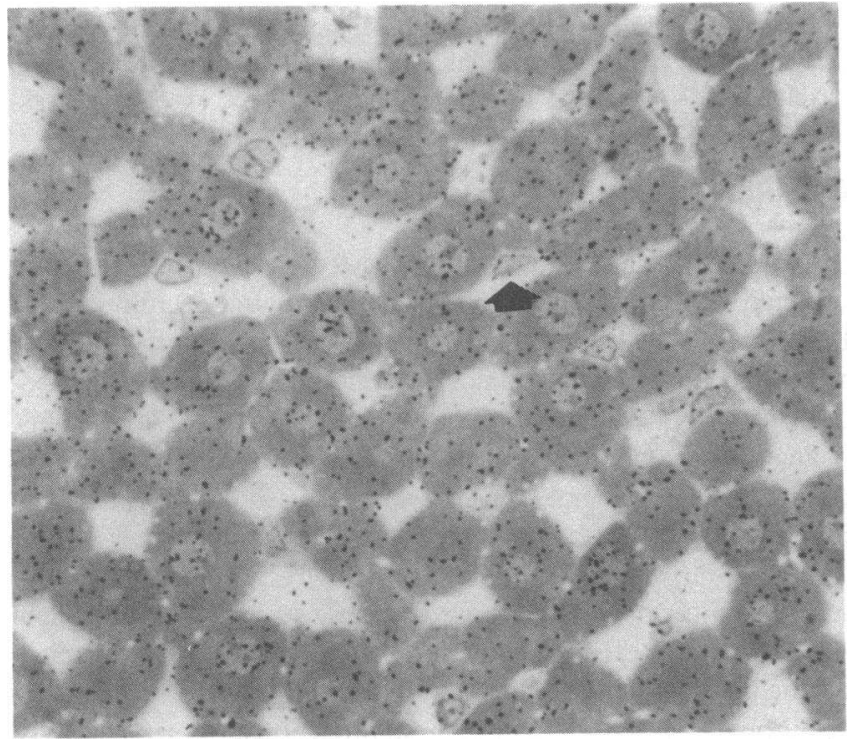

Figure 3. Autoradiogram of liver tissue showing location of iron. After a 10 -min perfusion with $1 \mu \mathrm{M}$ ferrous ${ }^{55} \mathrm{Fe}$ (plus $0.3 \mathrm{mM}$ ascorbate), the liver was fixed using glutaraldehyde and thin $(0.2-\mu \mathrm{m})$ sections coated with photographic emulsion and developed 4-8 wk later. Grains are primarily located over the interior of parenchymal cells; however, they are also seen over Kupffer cells (arrow). Few grains are seen over the sinusoidal spaces, confirming that grain location closely marks the cellular location of the iron.

which suggests that the molecular weight of the ferric-tricine and ferrous-tricine complexes are similar. The oxidation state of the ferrous and ferric iron solutions was monitored by the method of Bothwell et al. (10) and found to be stable for the periods employed.

Validation of the multiple-steady-state method. In 22 perfusions, the perfusate flow rate averaged $2.72 \pm 0.05 \mathrm{ml} \cdot \mathrm{min}^{-1} \cdot \mathrm{g}$ liver $^{-1}$ (mean \pm SEM). For all concentrations of ferrous and ferric iron studied (1-60 $\mu \mathrm{M})$, uptake reached steady-state within

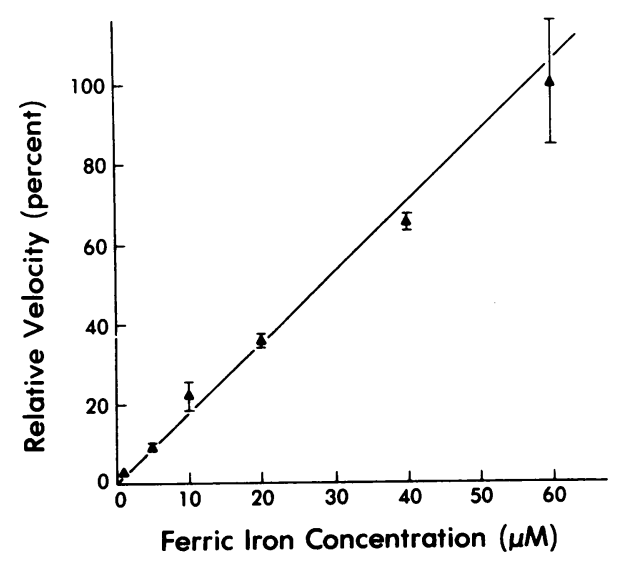

Figure 4. Rate of diffusion of ferric iron across a cellulose membrane in tricine buffer. Ferric iron diffused freely across a cellulose membrane (molecular weight cut-off, 2,000) for all concentrations used in the perfusion studies (1-60 $\mu \mathrm{M})$, which suggests high molecular weight aggregates are not formed in tricine buffers. Diffusion rates were similar to those found for ferrous iron (not shown). Mean initial velocities for three experiments are shown on an arbitrary scale with $95 \%$ confidence intervals.
$30 \mathrm{~s}$ after selection of a new solution. Perfusion with a single iron concentration for up to $24 \mathrm{~min}$ resulted in no decline in the uptake rate (Fig. 5), suggesting that little loss of transport capacity would be expected over the 12-min experimental period typically used. Each experiment was validated by reinfusion of the initial test solution after completion of the study. In all experiments, the resulting velocity was comparable to that seen initially (mean ratio, $0.90 \pm 0.20[\mathrm{SD}], P>0.25$ vs. 1.0 ), confirming preservation of transport function during the experiment.

Because we were concerned that saturation of the hepatic iron storage capacity might occur at higher concentrations of iron (resulting in increased rates of iron efflux from the liver), iron concentrations were measured in the wash solution after each test solution. In all cases, efflux rates were negligible with respect to uptake rates, and calculations indicated that $<1 \%$ of the total hepatic ${ }^{55} \mathrm{Fe}$ effluxed from the liver during a typical experiment. Similar saturation kinetics were seen when the sequence of perfusate solutions was reversed. Taken together, these results indicate that the liver remains viable for at least $15 \mathrm{~min}$ under the conditions of these experiments, and that each steadystate determination is effectively independent of previous determinations performed on the same liver.

Effect of transient anaerobiasis. As discussed previously, perfusion with anaerobic ferrous iron solutions for periods of $30 \mathrm{~s}$ appeared to be well tolerated by the liver. Nevertheless, to exclude the possibility that our results were in any way affected by the anaerobic period, control experiments were performed in which ferrous iron solutions containing $0.3 \mathrm{mM}$ ascorbate were oxygenated by passage through the lung immediately before they entered the liver. No differences were seen (Table I). This method was not used routinely because the additional deadspace associated with use of the lung greatly prolonged the time required to reach steady state.

Efficiency of uptake. At low concentrations ( $1 \mu \mathrm{M}), 63 \pm 4 \%$ (mean \pm SEM) of ferrous iron was extracted from tricine buffer in a single pass through the liver (Table I). Extraction of ferric iron was similar $(55 \pm 2 \%, P>0.1)$. Addition of $0.3 \mathrm{mM}$ ascorbate increased the extraction of ferrous iron slightly $(74 \pm 2 \%, P$ $<0.05$ ), while further addition of $1 \%$ albumin slightly reduced it ( $44 \pm 6 \%, P<0.0025)$. These differences could not be explained by variation in the perfusate flow rate (differences not significant).

Effect of physiologic coordinators. Uptake of low concentrations of ferrous and ferric iron from Krebs-bicarbonate solutions

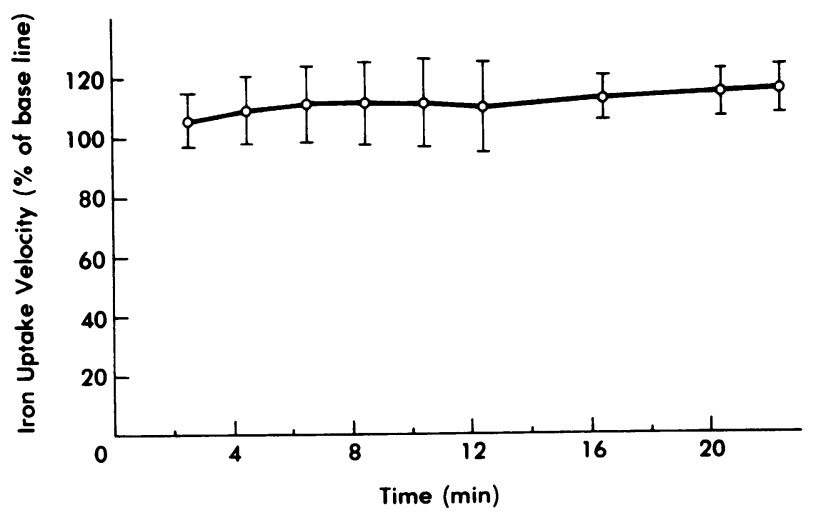

Figure 5. Time course of uptake. Conditions are the same as in Fig. 2. No decline in uptake is noted over a period of $30 \mathrm{~min}$. Typical experiments required $<12 \mathrm{~min}$. 
Table I. Uptake of Iron by the Perfused Rat Liver

\begin{tabular}{lllll}
\hline & Extraction & Apparent $K_{\mathrm{m}}$ & Apparent $\mathrm{V}_{\max }$ & Flow rate \\
\hline & $\%$ & $\mu M$ & $\mathrm{nmol} \cdot \mathrm{s}^{-1}$ & $\mathrm{ml} \cdot \mathrm{min}^{-1} \cdot \mathrm{gliver}$ \\
Ferrous iron & $63 \pm 4$ & $22 \pm 5$ & $38 \pm 7$ & $2.63 \pm 0.45$ \\
Ferrous iron plus ascorbate $(0.3 \mathrm{mM})$ & $74 \pm 2$ & $16 \pm 2$ & $32 \pm 5$ & $2.63 \pm 0.20$ \\
Ferrous iron plus ascorbate $(0.3 \mathrm{mM})$ and & & & & \\
$\quad$ albumin $(1 \%)$ & $44 \pm 7$ & $27 \pm 3$ & $40 \pm 2$ & $3.15 \pm 0.22$ \\
Ferrous iron plus ascorbate $(0.3 \mathrm{mM})$ and oxygen & $67 \pm 4$ & $30 \pm 19$ & $47 \pm 25$ & $2.41 \pm 0.06$ \\
Ferric iron & $55 \pm 2$ & $14 \pm 2$ & $24 \pm 2$ & $2.81 \pm 0.12$ \\
\end{tabular}

The fraction of the iron removed in a single-pass extraction was used to calculate the steady-state removal velocity for a series of test solutions containing graded concentrations of iron. Viability of each liver preparation was assessed as described in the text. Data for individual experiments were analyzed and the apparent $K_{\mathrm{m}}$ and $V_{\max }$ values were averaged. Mean values are shown with standard errors. All solutions contained Krebstricine buffer plus additions as noted. Ferrous solutions were anaerobic, except where noted.

in the presence of physiologic coordinating compounds was also highly efficient (Tables II and III). Similar high extractions were observed from ultrafiltered human serum.

Autoradiography. Fig. 3 shows the distribution of autoradiographic grains over a $0.2-\mu \mathrm{M}$ section of the liver prepared after perfusion with ferrous ${ }^{55} \mathrm{Fe}(1 \mu \mathrm{M})$ plus $0.3 \mathrm{mM}$ ascorbate for $10 \mathrm{~min}$. Most grains appear over parenchymal cells, although some grains are also seen over Kupffer cells (arrow). Few grains appear over the empty sinusoidal spaces, confirming that the iron is located within the hepatocytes.

Ferrous iron kinetics. Uptake of ferrous iron was saturable with an apparent $K_{\mathrm{m}}$ of $22 \pm 5 \mu \mathrm{M}$ (mean \pm SEM), and an apparent $V_{\max }$ of $38 \pm 7 \mathrm{nmol} \cdot \mathrm{min}^{-1} \cdot \mathrm{g} \mathrm{liver}^{-1}$ (Fig. 6). Saturation did not result from loss of viability, since similar results were obtained regardless of the order in which the solutions were perfused.

Effect of ascorbate. Addition of ascorbate $(0,3 \mathrm{mM})$ to the ferrous iron solutions had little effect on uptake parameters $\left(K_{\mathrm{m}}\right.$, $16 \pm 2 \mu \mathrm{M} ; V_{\max }, 32 \pm 5 \mathrm{nmol} \cdot \mathrm{min}^{-1} \cdot \mathrm{g} \mathrm{liver}^{-1} ; P>0.15$ for both). As previously noted, single-pass extraction increased slightly.

Effect of albumin. Addition of bovine albumin (1\%) to the ferrous iron solutions containing $0.3 \mathrm{mM}$ ascorbate increased the apparent $K_{\mathrm{m}}(27 \pm 3 \mu \mathrm{M}, P<0.01)$ but did not change the apparent $V_{\max }\left(40 \pm 2 \mathrm{nmol} \cdot \min ^{-1} \cdot \mathrm{g} \mathrm{liver}^{-1}, P>0.1\right)$. As previously noted, single-pass extraction decreased slightly.

Ferric iron kinetics. Uptake of ferric iron also displayed saturation kinetics (Fig. 7). The apparent $K_{\mathrm{m}}$ was $14 \pm 2 \mu \mathrm{M}$ and the apparent $V_{\max }, 24 \pm 2 \mathrm{nmol} \cdot \mathrm{min}^{-1} \cdot \mathrm{g} \mathrm{liver}^{-1}$. These values

Table II. Uptake of Ferrous Iron by the Perfused Rat Liver: Effect of Physiologic Coordinators

\begin{tabular}{llllll}
\hline $\begin{array}{l}\text { Coordinating } \\
\text { agent }\end{array}$ & $\begin{array}{l}\text { Ultrafiltered } \\
\text { serum }\end{array}$ & $\begin{array}{l}\text { Krebs } \\
\text { bicarbonate }\end{array}$ & Ascorbate & Histidine & $\begin{array}{l}\text { Human } \\
\text { albumin }\end{array}$ \\
\hline & & & $0.3 \mathrm{mM}$ & $0.3 \mathrm{mM}$ & $4 \%$ \\
Extraction \% & $75 \pm 4$ & $87 \pm 4$ & $78 \pm 3$ & $88 \pm 4$ & $18 \pm 2$ \\
No. & 3 & 3 & 3 & 3 & 3 \\
\hline
\end{tabular}

The fraction of ferrous iron extracted in a single-pass through the liver is shown for a series of solutions containing $1 \mu \mathrm{M}$ ferrous iron and a physiologic coordinator. All solutions, except ultrafiltered serum, contained Krebs-bicarbonate, and were maintained anaerobic by bubbling with $95 \% \mathrm{~N}_{2} / 5 \% \mathrm{CO}_{2}$. Flow rates were similar to ferrous tricine experiments (flow rate $=2.55 \pm 0.15 \mathrm{ml} \cdot \mathrm{min}^{-1} \cdot \mathrm{g}$ liver $\left.^{-1}\right)$. Mean values are shown with standard errors. Extraction of iron from all solutions, except that containing albumin, was highly efficient. were not significantly different from those for ferrous iron or ferrous iron plus ascorbate $(P>0.05)$.

\section{Discussion}

The liver plays a central role in iron metabolism both in normal individuals and in iron-overloaded individuals. Normally, $\sim 99 \%$ of the iron in plasma is bound to transferrin, while the remainder circulates as low molecular weight complexes or in association with other serum proteins such as albumin (6). Recent studies suggest that hepatic uptake from the transferrin-bound pool involves receptor-mediated endocytosis followed by dissociation of the iron from transferrin at the acid $\mathrm{pH}$ within the endosome (1-4). The liberated iron (presumably in the form of low molecular weight complexes) is then thought to diffuse across the membrane of the endocytic vesicle into the cytoplasm while the apotransferrin is recycled to the plasma. This process, which appears sensitive to the iron requirements of the animal (13), typically removes $<1 \%$ of the transferrin from the plasma as it passes through the liver (5).

Much less is known about the mechanism by which the liver removes NTB iron from plasma. Zimelman et al. (5) have reported rapid clearance of ferrous citrate by the recirculating perfused rat liver, while Grohlich et al. (14) (using iron concentrations considerably above those that occur in plasma) have found evidence for saturable uptake of ferric iron but not ferrous iron by suspensions of rat hepatocytes. Batey et al. (15) have shown

Table III. Uptake of Ferric Iron by the Perfused Rat Liver: Effect of Physiologic Coordinators

\begin{tabular}{llllll}
\hline $\begin{array}{l}\text { Coordinating } \\
\text { agent }\end{array}$ & $\begin{array}{l}\text { Ultrafiltered } \\
\text { serum }\end{array}$ & Citrate & Fructose & Oxalate & Glutamate \\
\hline & & $0.3 \mathrm{mM}$ & $0.3 \mathrm{mM}$ & $0.3 \mathrm{mM}$ & $0.3 \mathrm{mM}$ \\
& & $67 \pm 6$ & $90 \pm 2$ & $88 \pm 3$ & $87 \pm 1$ \\
Extraction \% & $58 \pm 1$ & 3 & 3 & 3 & 3 \\
No. & 3 & & & & \\
\hline
\end{tabular}

The fraction of ferric iron extracted in a single-pass through the liver is shown for a series of solutions containing $1 \mu \mathrm{M}$ ferric iron and a physiologic coordinator. All solutions, except ultrafiltered serum, contained Krebs-bicarbonate, and the pH maintained at 7.4 by bubbling with $95 \% \mathrm{O}_{2} / 5 \% \mathrm{CO}_{2}$. Flow rates were similar to ferric tricine experiments (flow rate $=3.11 \pm 0.17 \mathrm{ml} \cdot \mathrm{min}^{-1} \cdot \mathrm{g} \mathrm{liver}^{-1}$ ). Mean values are shown with standard errors. Extraction of ferric iron from all solutions was highly efficient. 


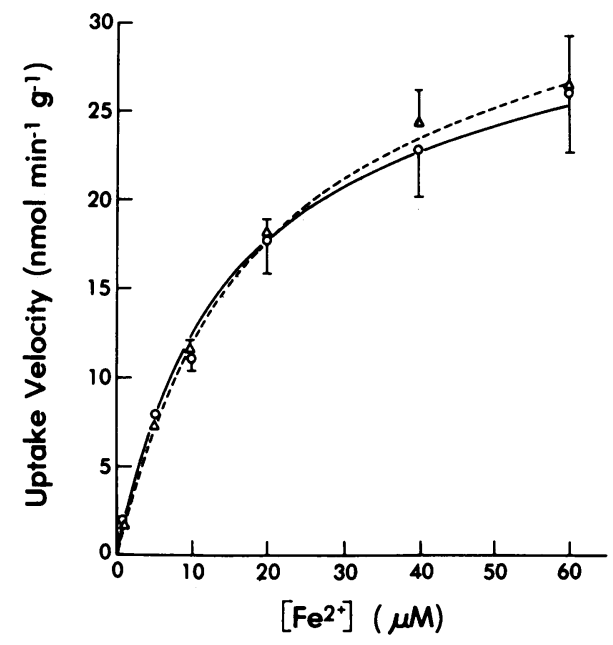

Figure 6. Uptake of ferrous iron vs. concentration. Both ferrous iron (triangles) and ferrous iron plus $0.3 \mathrm{mM}$ ascorbate (circles) showed saturation. Ascorbate produced no significant difference in the apparent kinetic constants (Table I). Points represent mean values for at least five experiments, and are shown with $95 \%$ confidence intervals.

that rat liver removes NTB iron from the serum of hemochromatotic patients. However, no systematic study of the uptake kinetics for NTB iron has yet appeared.

The current data indicate that hepatic removal of low molecular weight NTB iron complexes from serum is a highly efficient process, with $58-75 \%$ removed in a single-pass through the liver. Since the flow rate selected for these studies exceeds normal plasma flow by more than threefold, hepatic removal of NTB iron in vivo should be even more complete. Rapid removal of iron from the plasma as it passes through the liver should generate a range of iron concentrations within the hepatic sinusoids, with the periportal hepatocytes exposed to the highest values. In consequence, these hepatocytes would be expected to accumulate the most iron. Periportal iron accumulation is, in fact, characteristic of hemochromatosis (16) and acute iron poi-

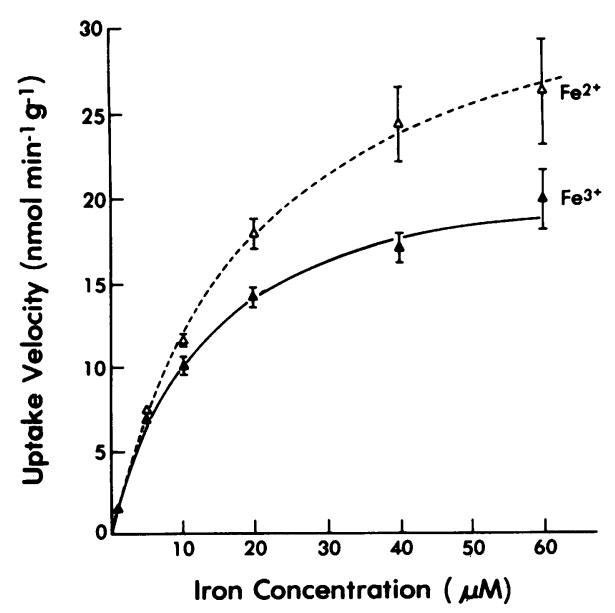

Figure 7. Uptake of ferric iron vs. concentration. Uptake of ferric iron $\left(\mathrm{Fe}^{+++}\right)$showed saturation. Results were not significantly different from ferrous iron uptake $\left(\mathrm{Fe}^{++}\right)$. Points represent mean values for at least five experiments, and are shown with $95 \%$ confidence intervals. soning (17). In contrast, uptake of transferrin-bound iron appears to be too inefficient to produce lobular concentration gradients (5) and thus cannot account for the observed iron distribution. These gradients thus suggest that most of the excess hepatic iron in hemochromatosis results from efficient uptake of NTB iron rather than from less efficient uptake of transferrin-bound iron.

Iron is highly toxic to many organ systems, including heart, pancreas, and pituitary (16). While iron can be toxic to the liver as well, toxicity appears to occur at higher tissue concentrations, permitting storage of excess body iron in the liver. We suggest here that an important factor in determining the rate of iron removal by the liver in iron-overloaded states is the degree of saturation of transferrin, since this largely determines the concentration of NTB iron in plasma $(9,18)$. If so, the liver may prevent excess absorbed iron from entering the systemic circulation by removing effectively all iron in excess of the binding capacity of transferrin. Indeed, it has been reported that orally absorbed iron in hemochromatosis patients is almost completely removed by the liver before it enters the systemic circulation (19). Such a mechanism would also explain why hepatic iron loading precedes iron deposition in other tissues (20).

Extrapolation of our results to in vivo conditions involves several assumptions, most importantly that the iron-tricine complexes studied are representative of the NTB iron pool in plasma. Tricine was selected over naturally occurring coordinating agents for the kinetic studies because it is a nonmetabolized amino acid that binds to, and effectively solubilizes, both ferrous iron and ferric iron (R. Nakon, personal communication). In addition, the buffering capacity of tricine allowed us to omit bicarbonate from the solutions, thus avoiding formation of poorly soluble carbonates at higher concentrations of ferrous iron that would have made interpretation of the data more difficult. Tricine appears to be well-tolerated by the liver, and has been previously used in perfused liver (21) and cell culture (22) studies with minimal toxicity. The only possible toxic effect noted in our study was a slight shrinkage of the cells that did not reduce their capacity to remove iron from the perfusate and that was not associated with ultrastructural evidence of toxicity. Thus, while we cannot exclude the possibility that replacement of bicarbonate with tricine had some effect on the results, it seems unlikely.

The availability of tricine-bound iron appears to be similar to that of iron bound to physiologic coordinators. Thus, perfusion with low concentrations of ferrous iron in the presence of excess ascorbate or histidine, both important coordinators of ferrous ion in plasma (6), resulted in comparable rates of extraction (Table II). Similar rates were seen when ferric iron was coordinated with its physiologic chelators (6), citrate, fructose, oxalate, and glutamate (Table III). Most significantly, both ferrous iron and ferric iron were efficiently removed from fresh ultrafiltered serum, which presumably retains normal concentrations of low molecular weight iron-coordinating compounds. Somewhat less ferrous iron was taken up from $4 \%$ solutions of human albumin, although extraction would still be relatively efficient at the slower flow rates in vivo. Moreover, only a small proportion of the NTB-iron in plasma is bound to albumin (6), suggesting that albumin binding should not significantly limit removal of NTB iron when other coordinating agents are present.

Perfusion solutions containing ferrous iron were kept anaerobic to prevent auto-oxidation and generation of potentially toxic oxygen radicals. The brief period of hypoxia necessary to 
measure uptake from these solutions appears to have been well tolerated by the liver. Indeed, previous studies have shown that the liver is remarkably tolerant of anaerobic conditions providing it is well glycogenated and the products of glycolysis are not allowed to accumulate (23). Furthermore, $30 \mathrm{~s}$ seems to be too brief a period to produce significant changes in intracellular energy metabolism (24). For all these reasons, the use of anaerobic perfusate solutions seems unlikely to have affected our results.

Uptake was saturable for ferric iron and for ferrous iron with and without added ascorbate. Only small differences in the kinetic parameters were observed for these different forms of iron, suggesting uptake in each case may occur by a common mechanism. Previous studies in other tissues have often found ferrous complexes to be more available for uptake than ferric. We suggest here that these differences may reflect the relative insolubility of most ferric iron complexes (6), since addition of tricine (which solubilizes both ferrous iron and ferric iron) led to similar rates of uptake in each case.

The observed saturation kinetics suggest a membrane carrier system may be involved in the uptake of NTB iron by the liver. However, other possible explanations must be considered. Apparent saturation could result if the iron formed high molecular weight aggregates at higher concentrations that were less available for uptake. However, no differences were seen in the uptake of ferrous and ferric iron, despite the fact that the ferric iron has a much greater tendency to aggregate (6). Moreover, both forms of iron readily crossed a low molecular weight cut-off dialysis membrane. Finally, addition of ascorbate (which would be expected to reduce aggregation by chelating the iron) had no effect on the observed saturation. Alternatively, apparent saturation could result from deterioration of the liver preparation or saturation of the intracellular iron binding capacity during the course of the experiment. Both of these possibilities are excluded by the careful validation of steady-state described previously. Our data cannot, however, exclude the possibility that saturation resulted from a rate-limiting metabolic process inside the liver (e.g., incorporation of the iron into ferritin), rather than a membrane carrier. In this case, the similar kinetic parameters for ferrous and ferric iron could reflect conversion of the iron to a common oxidation state before the rate-limiting process. Studies with membrane vesicles may be necessary to resolve this ambiguity.

Autoradiography showed that the NTB iron was predominantly removed by parenchymal cells, while removal by Kupffer cells appeared quantitatively much less important. This distribution is similar to that seen in hemochromatosis, but differs from that seen in hemosiderosis secondary to transfusional iron overload, in which much more of the iron is deposited in Kupffer cells.

The $0.6-1 \mu \mathrm{M}$ concentration of NTB iron typical of normal plasma (9) is well below that needed to saturate the hepatic removal mechanism $\left(K_{\mathrm{m}}, 14-20 \mu \mathrm{M}\right)$, confirming that uptake should be efficient for physiological NTB iron concentrations. The much higher concentrations of NTB iron (typically 5-15 $\mu \mathrm{M})$ characteristic of iron overload states (9) may reflect not only saturation of serum transferrin, but also reduced hepatic removal of NTB iron because of associated hepatic damage and/ or portosystemic shunting. Thus, the highest levels of NTB iron would be expected in patients whose livers are no longer able to efficiently remove this form of iron from plasma.

In summary, we have described a transport mechanism in the liver that removes low molecular weight iron complexes from plasma with high efficiency. This mechanism can account for both the selective accumulation of iron by the liver in ironoverload states and the periportal distribution commonly observed. The physiologic importance of this transport mechanism remains uncertain. However, it may serve to prevent toxic concentrations of NTB iron from accumulating in the systemic circulation.

\section{Acknowledgments}

The authors gratefully acknowledge the contributions of Dr. Albert Jones and Gary Hradek (Electron Microscopy Core Facility), and Dr. Vojtech Licko (Biomathematics Core Facility).

This work was supported by research grant AM 32898 (Dr. Weisiger), Liver Core Center grant AM 26743, and by training grant AM 07007 (Dr. Wright) from the National Institutes of Health.

\section{References}

1. Sibille, J. C., J. N. Octave, Y. J. Schneider, A. Trouet, and R. R. Crichton. 1982. Transferrin protein and iron uptake by cultured hepatocytes. FEBS (Fed. Eur. Biochem. Soc.) Lett. 150:365-369.

2. Young, S. P., and P. Aisen. 1981. Transferrin receptors and the uptake and release of iron by isolated hepatocytes. Hepatology (Baltimore). 1:114-119.

3. lacopetta, B. J., and E. H. Morgan. 1983. The kinetics of transferrin endocytosis and iron uptake from transferrin in rabbit reticulocytes. $J$. Biol. Chem. 258:9108-9115.

4. Van Renswoude, J., K. R. Bridges, J. B. Harford, and R. D. Klausner. 1982. Receptor mediated endocytosis of transferrin and the uptake of Fe in K 562 cells: identification of a nonlysosomal acidic compartment. Proc. Natl. Acad. Sci. USA. 79:6186-6190.

5. Zimelman, A. P., H. J. Zimmerman, R. McLean, and L. R. Weintraub. 1977. Effect of iron saturation of transferrin on hepatic iron uptake: an in vitro study. Gastroenterology. 72:129-131.

6. May, P. M., D. R. Williams, and P. W. Linder. 1980. Biological significance of low molecular weight iron (III) complexes. In Metal Ions in Biological Systems. H. Sigel, editor. Marcel Dekker Inc., New York. 29-76.

7. Sarkar, B. 1970. State of iron (III) in normal human serum: low molecular weight and protein ligands besides transferrin. Can. J. Biochem. 48:1339-1350.

8. Hershko, C., G. Graham, G. W. Bates, and E. A. Rachmilewitz. 1978. Nonspecific serum iron in thalassaemia: an abnormal serum iron fraction of potential toxicity. Br. J. Haematol. 40:255-263.

9. Batey, R. G., P. Lai Chung Fong, S. Shamir, and S. Sherlock. 1980. A non-transferrin bound serum iron in idiopathic hemochromatosis. Dig. Dis. Sci. 25:340-346.

10. Bothwell, T. H., M. E. Conrad, J. D. Cook, W. H. Crosby, J. Fielding, L. Hallberg, G. Izak, M. Layrisse, and W. N. M. Ramsay. 1971. Proposed recommendations for measurement of serum iron in human blood. J. Clin. Pathol. 24:334-335.

11. Hamilton, R. L., M. N. Berry, M. C. Williams, and E. M. Severinghaus. 1974. A simple and inexpensive membrane "lung" for small organ perfusion. J. Lipid Res. 15:182-186.

12. Hems, R., B. D. Ross, M. N. Berry, and H. A. Krebs. 1966. Gluconeogenesis in the perfused rat liver. Biochem. J. 101:284-292.

13. Wilms, J., and R. Batey. 1983. Effect of iron stores on hepatic metabolism of transferrin-bound iron. Am. J. Physiol. 244:G138-144.

14. Grolich, D., C. G. D. Morley, and A. Bezkorovainy. 1979. Some aspects of iron uptake by rat hepatocytes in suspension. J. Biochem. (Tokyo). 10:797-802.

15. Batey, R. G., S. Shamir, and J. Wilms. 1981. Properties and 
hepatic metabolism of non-transferrin-bound iron. Dig. Dis. Sci. 26 1084-1088.

16. Edwards, C. Q., M. M. Dadone, M. H. Skolnick, and J. P. Kushner. 1982. Hereditary hemochromatosis. Clin. Haematol. 11:411-435.

17. Ganote, C. E., and G. Nahara. 1973. Acute ferrous sulfate hepatotoxicity in rats. Lab. Invest. 28:426-436.

18. Wheby, M. S. 1984. Liver damage in disorders of iron overload. A hypothesis. Arch. Intern. Med. 144:621-622.

19. Fawwaz, R. A., H. S. Winchell, M. Pollycove, and T. Sargent. 1967. Hepatic iron deposition in humans. Blood. 30:417-424.

20. Valburg, L. S., J. B. Simon, P. N. Manley, W. E. Corbett, and
J. Ludwig. 1975. Distribution of storage iron as body iron stores expand in patients with hemochromatosis. J. Lab. Clin. Med. 86:479-484.

21. Van Dyke, R. W., J. E. Stephens, and B. F. Scharschmidt. 1982. Effects of ion substitution on bile acid-dependent and -independent bile formation by rat liver. J. Clin. Invest. 70:505-517.

22. Gardner, R. S. 1969. The use of tricine buffer in animal tissue cultures. J. Cell Biol. 42:320-321.

23. Woods, H. F., and H. A. Krebs. 1971. Lactate production in the perfused rat liver. Biochem. J. 125:129-139.

24. Ji, S., J. J. Lemasters, V. Christenson, and R. G. Thurman. 1982. Periportal and pericentral pyridine nucleotide fluorescence from the surface of the perfused liver. Proc. Natl. Acad. Sci. USA. 79:5415-5419. 